\title{
Mbd3 and deterministic reprogramming
}

\author{
Paul Bertone, Brian Hendrich and José C.R. Silva
}

Wellcome Trust - Medical Research Council Stem Cell Institute University of Cambridge, Gleeson Building, Tennis Court Road, Cambridge CB2 1QR, UK

Correspondence: pb407@cam.ac.uk (PB), bdh24@cam.ac.uk (BH), jcs64@cam.ac.uk (JCRS)

Embryonic development requires the activity of the Nucleosome Remodeling and Deacetylase (NuRD) complex. NuRD functionality can be ablated by rendering cells devoid of methyl-CpG-binding domain protein 3 (Mbd3), a critical component that confers stability to the complex ${ }^{1}$. Previous studies noted that $M b d 3 \%$ embryonic stem (ES) cells misregulate a subset of pluripotency-associated genes, and subsequently fail to engage in cell differentiation into embryonic lineages when self-renewal requisites (e.g. LIF) are withdrawn from culture media $^{2-3}$. Components of the NuRD complex have been shown to interact with Oct4 and Nanog, two important transcription factors operative in the production of iPS cells ${ }^{4-7}$. Thus, elucidating the role of Mbd3/NuRD in the reprogramming process is of relevance to the field.

Rais et al. reported the remarkable observation that suppressing formation of the NuRD complex by depleting Mbd3 promotes near 100\% induction of cells reprogrammed to pluripotency8. This was an important result, as typical iPS cell conversion rates are extremely low; such an increase in reprogramming efficiency would represent a considerable advance in the production of iPS cells for research and therapeutic applications. However, concurrent and independent work from our labs obtained contrasting results, where a profound reduction in reprogramming efficiency was observed from cells where $M b d 3$ had been ablated ${ }^{9}$.

We sought to understand this discrepancy, in part by analyzing the data provided by Rais et al. The study employs cells containing a single functional allele of $M b d 3$ that can be conditionally deleted $\left(M b d 3^{\mathrm{n} /} / \mathrm{-}^{10}\right.$, and that are also transgenic for several constructs inserted into the genome by random integration: a doxycycline (DOX)inducible polycistronic reprogramming cassette, a promoter-driven Oct4-GFP reporter, and a constitutive mCherry reporter used for quantification of colony sizes and single-cell deposition by flow sorting. Performance

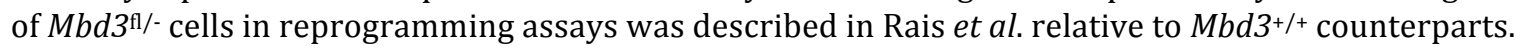

A gene expression dataset was produced for the study, where $M b d 3^{\mathrm{fl} /-}$ and $\mathrm{Mbd3^{+/+ }}$ mouse embryonic fibroblasts (MEFs) were profiled on Affymetrix arrays during a reprogramming timecourse. Comprehensive analysis of this experiment is precluded by its design: only four time points are represented, one of those is inconsistent between experiment and control samples (taken at 8 vs 11 days), and no replicates were provided. Nevertheless, differential expression analysis reveals highly similar outcomes in each condition (Fig. 1A), with little divergence among pluripotency genes during induction of $M b d 3$ heterozygous and wild-type cells (Fig. 1B).

A

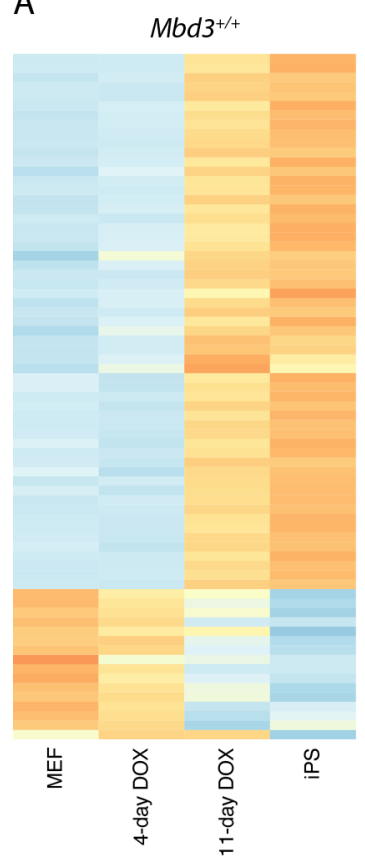

$M b d 3^{\text {th }}$

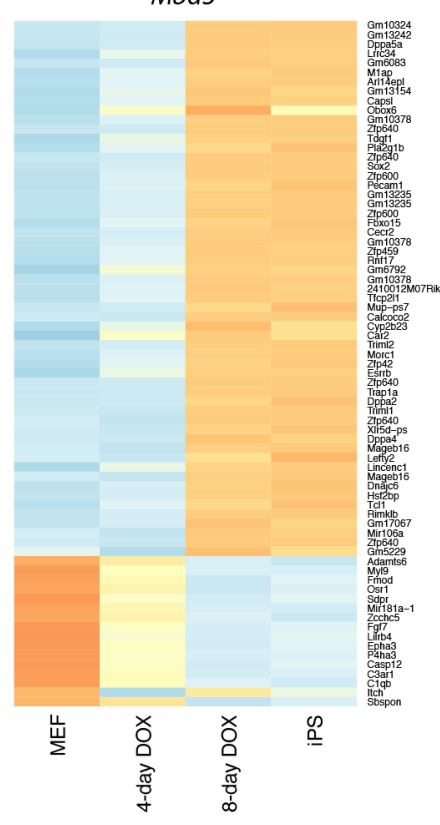

B

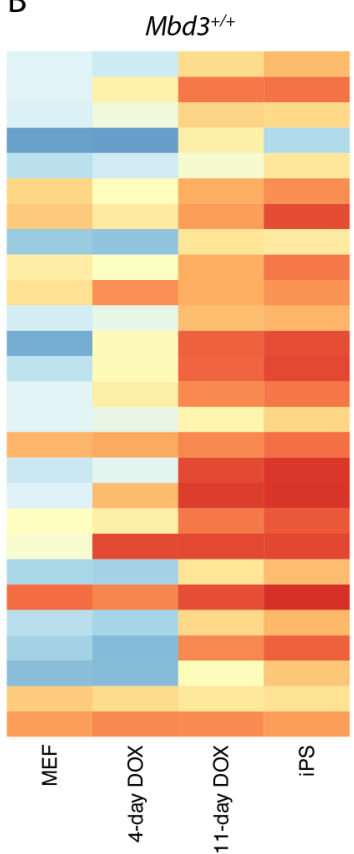

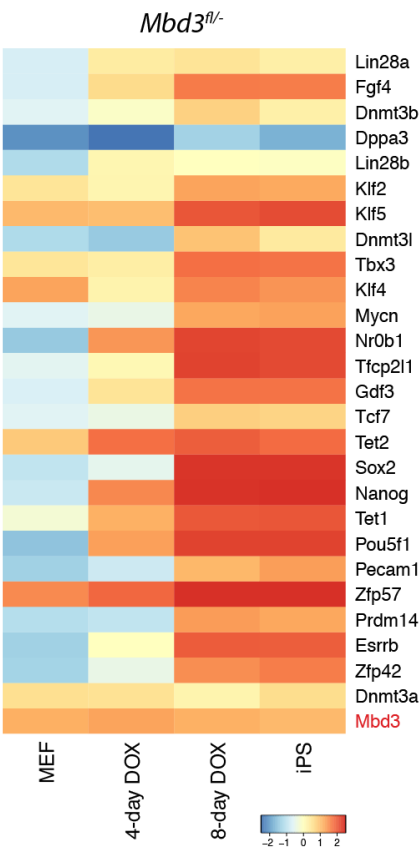

Figure 1. A) Microarray data from Rais et al. indicate similar gene expression patterns from $M b d 3^{+/+}$and $M b d 3^{\text {fl/- }}$ cells during a timecourse of doxycycline-induced reprogramming ( $Z$-score transformed $\log _{2}$ expression). B) Pluripotency factors show little variation between $M b d 3^{+/+}$and $M b d 3^{\mathrm{fl} /-}$ lines. $M b d 3$ is expressed at comparable levels in both conditions (bottom row). 
A

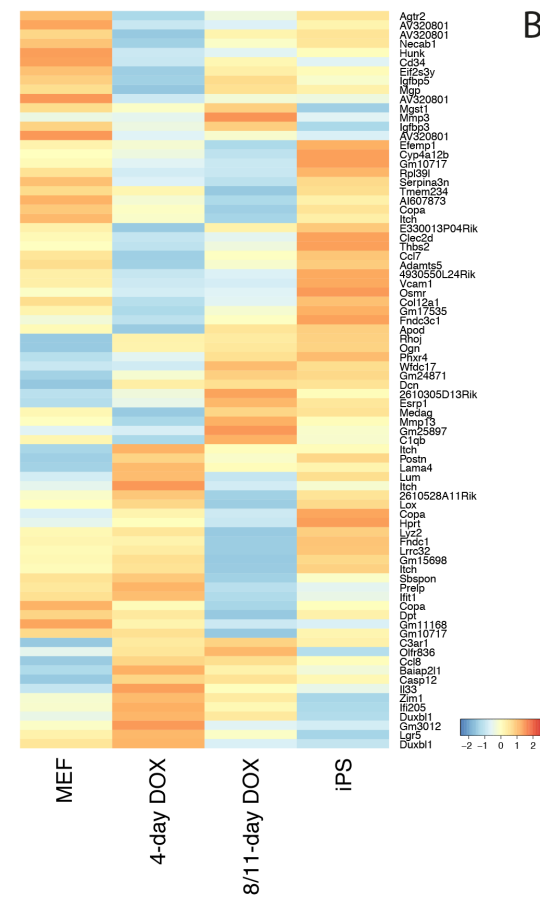

B
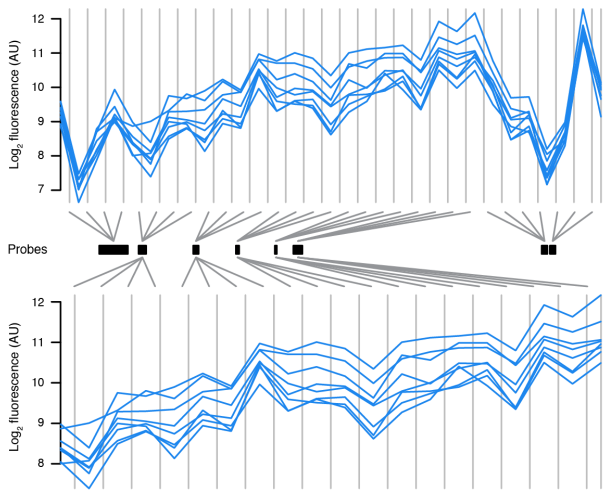

Mbd3 (- strand)

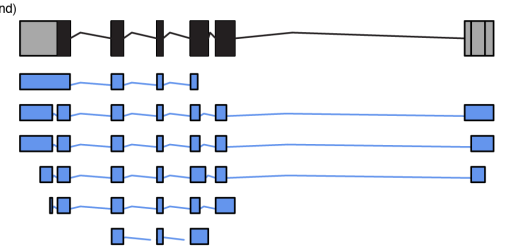

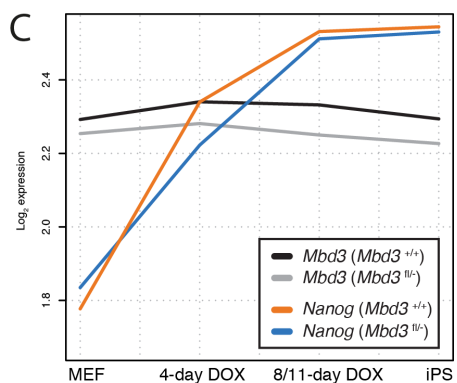

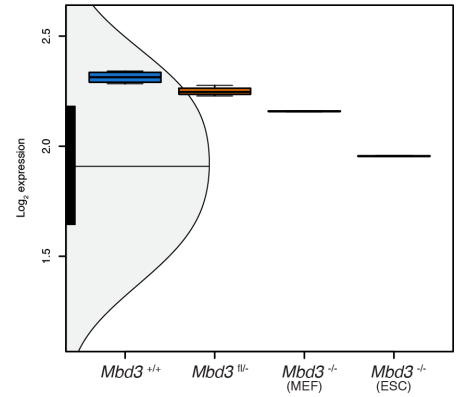

Figure 2. A) Genes exhibiting the most discrepant changes between $M b d 3^{+/+}$and $M b d 3^{\mathrm{fl} /-}$ cells profiled over the timecourse. B) Probe-level intensity data from the complete $M b d 3$ probeset (upper data tracks) and reduced probeset excluding probes to exon 1 and UTRs remaining in the knockout allele (lower data tracks; see Methods). Mbd3 locus and transcript isoforms are depicted below (antisense orientation). C) Comparable expression of $\mathrm{Mbd3}$ and $\mathrm{Nanog}$ in $\mathrm{Mbd3^{+ } / +}$ and $\mathrm{Mbd} 3^{\mathrm{fl} / \text { - cells over }}$ the time series (top); Mbd3 is transcribed in heterozygous and Mbd3\%-MEFs at 85\% and 66\% wild-type levels, respectively (bottom). Continued expression in "null" cells may be due to reprogramming of MEF lines after Cre excision was performed, thereby selecting for iPS cell colonies where reversion to pluripotency was facilitated by the presence of an intact allele.

The greatest fold-change differences between experiment and control cells over the time series arise from a discordant set of genes devoid of canonical pluripotency regulators (Fig. 2A), suggesting the dominating effect to be due to biological variation expected from distinct and independently derived cell lines. However, the degree of such variability is impossible to assess in the absence of experimental replication.

Rais et al. evaluated the potential of $M b d 3$ depletion primarily in the $M b d 3^{\mathrm{fl} /}$ - heterozygous background without deleting the remaining allele. This was predicated on the notion that $M b d 3$ displays hypomorphic expression, based on the authors' estimate of protein abundance in $\mathrm{Mbd} 3^{\mathrm{n} /-}$ - cells at $20 \%$ that of wild-type levels. Markedly different results were obtained in two independent studies by our groups $\mathrm{s}^{9,11}$, where near wild-type Mbd3 protein abundance was measured from cells of this genotype regardless of the culture conditions used.

Analysis of the microarray data from Rais et al. shows Mbd3 transcript levels in heterozygous cells to be $85 \%$ relative to $\mathrm{Mbd}^{+/+}$controls, consistent with the behavior previously observed. Although few experiments in Rais et al. involve cells in which the floxed allele had been deleted to assess reprogramming efficiency in null $\left(\mathrm{Mbd3}^{-} /\right)$conditions, this was performed and expression data from those cells were included in the dataset. $M b d 3^{-}$MEFs profiled in the study express $M b d 3$ transcript at $66 \%$ wild-type levels and $78 \%$ relative to $M b d 3^{\text {fl/ }}$ cells (Fig. 2B,C), calling into question the effective depletion of Mbd3 protein and impairment of NuRD function as a causal factor contributing to the reported increase in reprogramming efficiency.

Much of the Rais et al. study makes use of a reporter of Pou5f1 (Oct4) expression, consisting of the complete endogenous Oct4 regulatory sequence linked to GFP ${ }^{12}$. Analysis of the ChIP-seq data provided by Rais et al. allows inspection of the promoter fragment used to regulate GFP expression in the reporter lines. The Oct4 promoter region contains several well-characterized elements ${ }^{13}$, notably the proximal and distal enhancers (PE and DE). Their functions have been previously defined using genomic Oct4 fragment (GOF)-18, an $18 \mathrm{~kb}$ intact sequence, and derivatives where regions encompassing each enhancer have been deleted $(\triangle \mathrm{PE} \text { and } \triangle \mathrm{DE})^{14}$.

Sequencing reads corresponding to the reporter transgene DNA map to the endogenous Oct4 locus in the reference genome at high copy number (Fig. 3A). Alignments from $M b d 3^{\text {fl/ }}$ - cells are contiguous and span the entire promoter region. In contrast, a gap in read coverage is present in $\mathrm{Mbd}^{+/++}$cells corresponding to the segment deleted in the $\triangle \mathrm{PE}$ construct (Fig. 3B). The intact GOF-18 construct is solely described in Rais et al. and indicated schematically in Extended Data Figure 3a (top). The full Oct4 promoter is illustrated with PE and DE elements included, implying that all cells received this plasmid. In contrast, it is evident that $M b d 3^{\mathrm{H} /-}$ and $\mathrm{Mbd3^{+/+ }}$ control cells harbor different variants of GOF-18 reporter constructs. 
A

WT iPS gDNA (SRR950345)

B
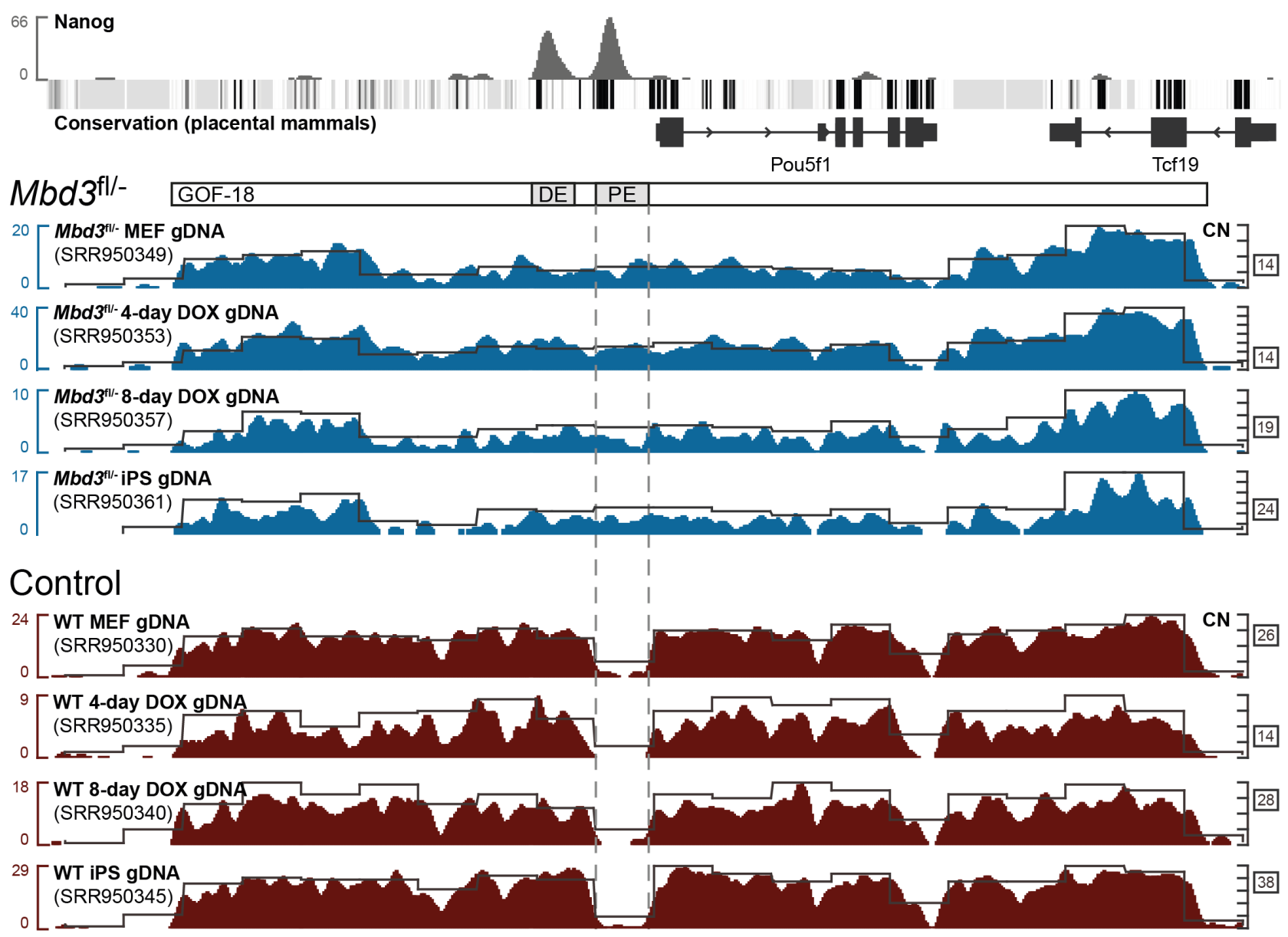

Figure 3. Sequencing data from whole-cell extract (WCE) genomic DNA libraries reveals numerous transgene copies relative to genomic background (A), with $M b d 3^{\text {fl/- }}$ (blue) and $M b d 3^{+/+}$(red) Oct4-GFP reporter lines harboring intact GOF-18 and GOF$18 \triangle \mathrm{PE}$ constructs, respectively (B). Proximal and distal enhancer regions of the Oct4 promoter are denoted, together with sequence conservation and Nanog binding site occupancy from an independent dataset ${ }^{28}$. Scales indicate read count (left) and transgene copy range estimated at $1 \mathrm{~kb}$ intervals (right). 


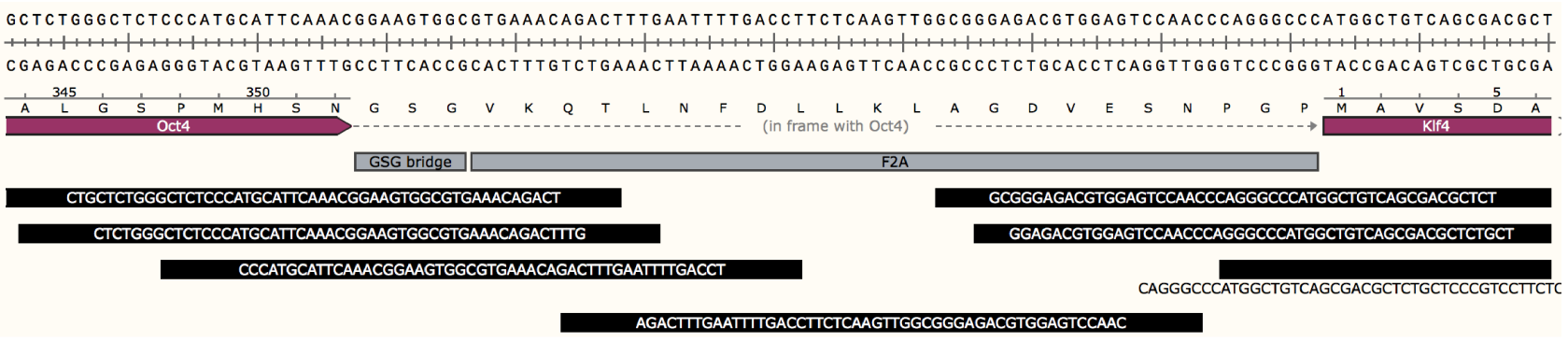

ATGGTGAGCAAGGGCGAGGGGATAACATGGCCATCATCAAGGAGTTCATGCGCTTCAAGGTGCACATGGAGGGCTCCGTGAACGGCCACGAGTTCGAGATCGAGGGCGAGGGCGAGGC

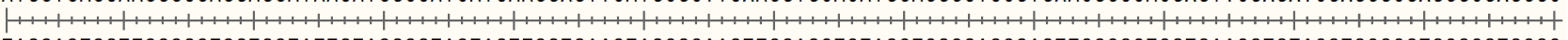
ACCACTCGTTCCCGCTCCTCCTATTGTACCGGTAGTAGTTCCTCAAGTACGCGAAGTTCCACGTGTACCTCCCGAGGCACTTGCCGGTGCTCAAGCTCTAGCTCCCGCTCCCGCTCCCG

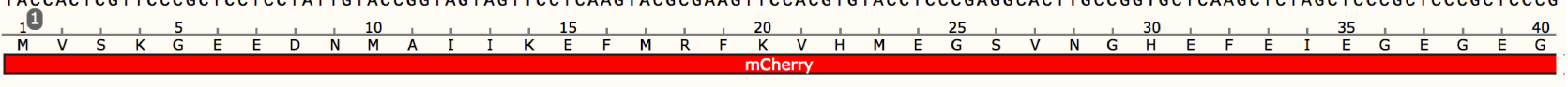

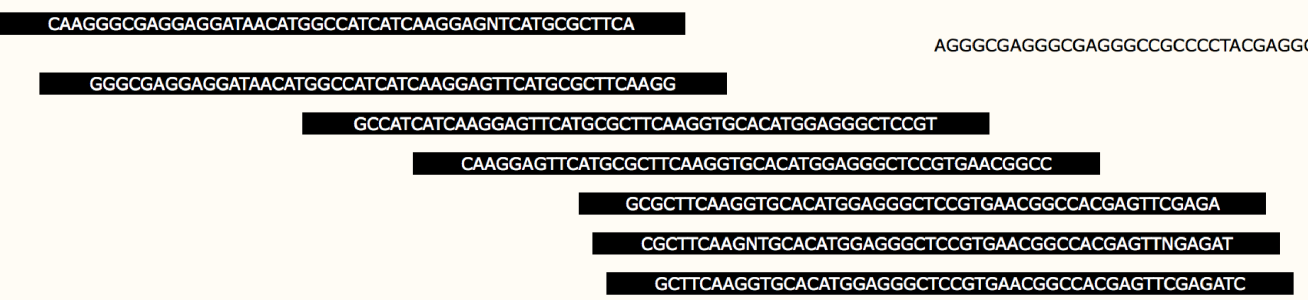

Figure 4. Sequencing data confirm $\mathrm{Mbd3}^{+/+}$cells harbor the STEMCCA polycistronic cassette (top) and mCherry (bottom). Together with the GOF-18 $\triangle$ PE Oct4-GFP reporter (Fig. 3, 5) the complete reprogramming and reporter system is present, suggesting the use of these cells as controls in the assays listed in Table 1.

The reprogramming system described in Rais et al. employed a polycistronic reprogramming cassette (STEMCCA) ${ }^{15}$ as well as a constitutive mCherry reporter used for quantification of colony sizes and single-cell

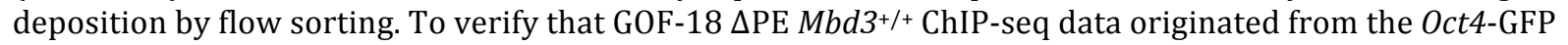
reporter cells used throughout the study, we identified sequencing reads corresponding to mCherry and parts of the STEMCCA construct design, including the internal ribosomal entry site (IRES) and 2A peptide sequences linking each reprogramming factor (Fig. 4).

\section{Analysis and commentary}

To properly evaluate the role of the NuRD complex by $M b d 3$ depletion, both copies of the gene must be

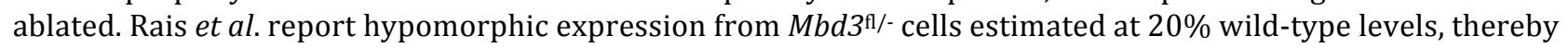
justifying the use of a heterozygous cell line to represent a functional Mbd3 mutant. That assessment disagrees with our experience and the authors' microarray data, where robust $M b d 3$ expression is apparent in both $M b d 3^{\mathrm{H} /-}$ and $M b d 3^{\%}$ lines. The latter finding may have arisen from incomplete Cre excision and/or positive selection of reprogramming-competent cells with an intact $M b d 3$ allele. This suggests that differences in reprogramming kinetics are unlikely to be related to Mbd3 depletion, and indeed transcriptional states are comparable between the experiment and control cells profiled in the study.

Nonetheless, substantial improvements in reprogramming efficiency are described in Rais et al. Dramatic enhancement of pluripotency induction is reported from assays in which GFP was used as a readout for imaging and flow cytometry. Sequencing data from the study reveal that $M b d 3^{+/+}$cells were transfected with an Oct4-GFP reporter based on the GOF-18 $\triangle \mathrm{PE}$ construct, whereas Mbd3/1/- cells harbor an intact GOF-18 promoter fragment. Oct4 is expressed in a wider repertoire of tissues and cell types than embryonic stem cells ${ }^{16-19}$ and reporters based on the intact GOF-18 construct display similarly broad activity ${ }^{12,14}$. The PE is the most highly conserved region of the Oct4 promoter in eutheria and also drives transcription in post-implantation embryos. Deleting the PE confines expression to naïve pluripotent cells, and thus a construct lacking the PE effectuates a much more stringent reporter of authentic reprogramming outcomes.

Differential application of a promiscuous test reporter and a considerably weaker control compromises the study design and undermines the conclusions drawn. An invalid experimental setup is imposed where no combination of Oct4-GFP reporter lines can be legitimately compared, as the two constructs have been applied in a mutually exclusive fashion to the experiment and control groups (Fig. 5). This applies to all ES-derived and iPSderived MEFs where Oct4-GFP+ selection or quantification was used to establish differential reprogramming efficiency. No scientific motivation for comparative evaluation of alternate Oct4-GFP reporters is described in Rais et al., and use of the $\triangle \mathrm{PE}$ variant is not declared. Thus the paper is lacking a key methodological disclosure essential for accurate interpretation of the results. 
bioRxiv preprint doi: https://doi.org/10.1101/013904; this version posted January 16, 2015. The copyright holder for this preprint (which was not certified by peer review) is the author/funder, who has granted bioRxiv a license to display the preprint in perpetuity. It is made available under aCC-BY 4.0 International license.

Table 1. Exhibits from Rais et al. presenting data based on Oct4-GFP quantification to assess reprogramming efficiency.

\begin{tabular}{|c|c|c|}
\hline Figure & Assay & Interpretation \\
\hline $1 \mathrm{f}$ & Primordial germ cell derivation & $\begin{array}{l}\text { p.66: "Single cell isolated } M b d 3^{\mathrm{ft} /-} \text { Oct4-GFP1 E8.5 PGCs from chimaeric } \\
\text { mice were proficient in forming EG cell colonies and lines (.95\% } \\
\text { efficiency), whereas PGCs isolated from chimaeras that were } \\
\text { generated by micro-injecting } M b d 3^{+/+} \text {or } M b d 3^{\text {fl/- }} \text { cells carrying an } \\
\text { exogenous } M b d 3 \text { transgene reprogrammed at less than } 10 \% \text { efficiency } \\
\text { (Fig. 1f)." }\end{array}$ \\
\hline Extended Data 3c & $\begin{array}{l}\text { Oct4-GFP expression from reprogrammed cells } \\
\text { and intermediates }\end{array}$ & \multirow{4}{*}{$\begin{array}{l}\text { p.66: "Notably, } 95 \% \text { of } M b d 3^{\mathrm{fl} /-} \text { and } M b d 3^{-{ }^{-}} \text {cells were Oct4-GFP }{ }^{+} \text {at } \\
\text { day } 10 \text {, whereas only levels up to } 18 \% \text { were observed in control } \\
M b d 3^{+/+} \text {fibroblasts (Fig. 2a)." }\end{array}$} \\
\hline Extended Data 3d & $\begin{array}{l}\text { Oct4-GFP expression from reprogrammed cells } \\
\text { and intermediates }\end{array}$ & \\
\hline Extended Data $3 \mathrm{f}$ & $\begin{array}{l}\text { Oct4-GFP expression from reprogrammed cells } \\
\text { and intermediates }\end{array}$ & \\
\hline $2 a$ & $\begin{array}{l}\text { Reprogramming efficiency from } M b d 3^{+/+} \\
M b d 3^{\mathrm{fl} /-} \text { and } M b d 3^{-/ /} \text {cells }\end{array}$ & \\
\hline $2 b$ & $\begin{array}{l}\text { Matrix of reprogramming outcomes } \\
\text { (secondary iPS cells) }\end{array}$ & $\begin{array}{l}\text { p.66: "Single cell sorting of secondary mCherry } \mathrm{Mbd}^{\mathrm{ft} /-} \text { mouse } \\
\text { embryonic fibroblasts (MEFs) and subsequent reprogramming in 2i/LIF } \\
\text { plus doxycycline conditions reproducibly yielded } 100 \% \text { iPS cell } \\
\text { derivation efficiency by day } 8 \text {. Wild-type cells reprogrammed under } \\
\text { identical conditions, no more than } 20 \% \text { of clones reactivated Oct4-GFP } \\
\text { (Fig. 2b)." }\end{array}$ \\
\hline Extended Data 3e & $\begin{array}{l}\text { Oct4-GFP expression from reprogrammed cells } \\
\text { and intermediates }\end{array}$ & $\begin{array}{l}\text { p.67: "High single-cell reprogramming efficiency rates were obtained } \\
\text { from a variety of adult progenitor and terminally differentiated cells } \\
\text { (Fig. } 2 \mathrm{~d} \text { and Extended Data Fig. } 3 \mathrm{e} \text {,f)." }\end{array}$ \\
\hline $2 \mathrm{e}$ & $\begin{array}{l}\text { Imaging of Oct4-GFP }{ }^{+} \text {vs mCherry }{ }^{+} \mathrm{Mbd}^{+/+} \text {and } \\
\mathrm{Mbd3}^{\mathrm{fl} /-} \text { colonies }\end{array}$ & $\begin{array}{l}\text { p.67: "By day } 6 \text { after doxycycline induction, } .98 \% \text { of } M b d 3^{\mathrm{fl} /-} \text { clonal } \\
\text { populations reactivated the Oct4-GFP pluripotency marker, whereas } \\
\text { only up to } 20 \% \text { efficiency was detected in control samples } \\
\text { reprogrammed in identical growth conditions (Fig. } 2 \mathrm{e}, \mathrm{f}) . "\end{array}$ \\
\hline $2 f$ & $\begin{array}{l}\text { Secondary reprogramming assay comparing } \\
\text { Oct4-GFP }{ }^{+} M b d 3^{+/+} \text {and } M b d 3^{\mathrm{fl} /-} \text { colonies (top) } \\
\text { and cells (bottom) }\end{array}$ & $\begin{array}{l}\text { p.67: "By day 6, approximately } 85 \% \text { of cells within each individual } \\
\text { Mbd3 clonal population became Oct4-GFP+ cells, whereas }<2 \% \text { of cells } \\
\text { within successfully reprogrammed } M b d 3^{+/} \text {clones turned on the Oct4- } \\
\text { GFP marker (bottom panel in Fig. } 2 \mathrm{f} \text { )." }\end{array}$ \\
\hline Extended Data 4a & $\begin{array}{l}\text { Flow sorting of Oct4-GFP } \mathrm{Mbd}^{+/+} \text {and } \\
M b d 3^{\mathrm{ft} /} \text { cells }\end{array}$ & $\begin{array}{l}\text { p.67: "Detection of Oct4-GFP by flow cytometry on polyclonal } \\
\text { populations demonstrated similar iPS cell reprogramming kinetics } \\
\text { (Extended Data Fig. 4a)." }\end{array}$ \\
\hline Extended Data $4 \mathrm{~b}$ & Time course of lentiviral transduction & $\begin{array}{l}\text { p.67: "Re-infection with lentiviruses encoding } M b d 3 \text {, but not } M b d 2 \text {, } \\
\text { before day } 5 \text { of reprogramming had a profound inhibitory effect on iPS } \\
\text { cell generation from } M b d 3^{\mathrm{f} / /}-\mathrm{MEFs} \text {, whereas re-infection after day } 5 \\
\text { had a diminished effect (Extended Data Fig. } 4 \mathrm{~b}) . "\end{array}$ \\
\hline $3 b$ & Secondary reprogramming assay & $\begin{array}{l}\text { p.67: "After the depletion of } M b d 3 \text { expression, we were not able to } \\
\text { isolate stable, partially reprogrammed cells that did not reactivate } \\
\text { Oct4-GFP or Nanog-GFP and could be stably expanded in vitro, as } \\
\text { typically can be obtained from OSKM-transduced wild-type somatic } \\
\text { cells (Fig. 3b)." }\end{array}$ \\
\hline $3 c$ & Flow sorting of Oct4-GFP ${ }^{+}$cells & $\begin{array}{l}\text { p.67: "Notably, by introducing Mbd3 siRNA, all clones markedly turned } \\
\text { on Oct4-GFP or Nanog-GFP pluripotency markers after continued } \\
\text { OSKM expression in 2i/LIF (Fig. 3c)." [only Oct4-GFP data are shown] }\end{array}$ \\
\hline $5 e$ & Oct4-GFP $^{+}$cells in reprogramming assay & $\begin{array}{l}\text { p.70: "Mbd3 mutants with a compromised ability to interact with } \\
\text { OSKM reprogramming factors directly (Extended Data Fig. 9d) were } \\
\text { deficient in reducing reprogramming efficiency of } \mathrm{Mbd3}^{\mathrm{fl} / \mathrm{-}} \text { somatic } \\
\text { cells, supporting the notion that direct OSKM-Mbd3 interactions are } \\
\text { important for inhibiting iPS cell formation (Fig. 5e)." }\end{array}$ \\
\hline
\end{tabular}



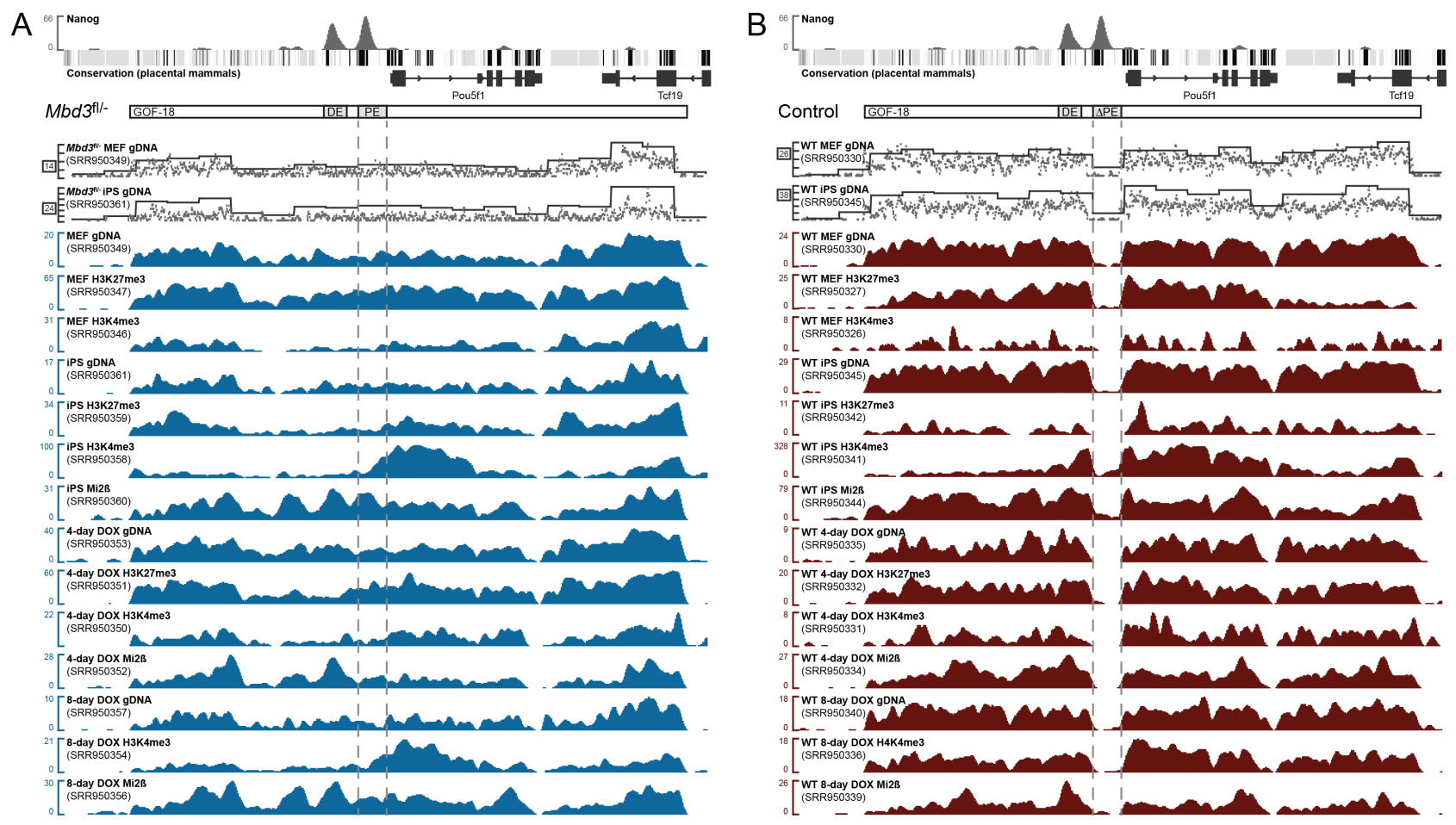

Figure 5. Data from equivalent ChIP-seq profiles indicate a 1:1 correspondence between the intact GOF-18 promoter

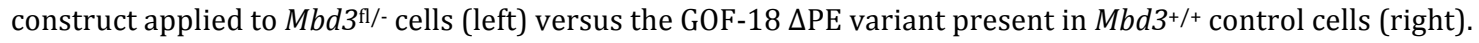

The line of investigation presented in Rais et al. heavily relies on Oct4-GFP expression as a proxy for the reversion of somatic cells to pluripotency. Differences in reporter activity arising from the tandem use of intact GOF-18 and GOF-18 $\triangle$ PE constructs may have adversely affected a significant number of assays and conclusions presented in the study (Table 1). The trend depicted in Figure $2 \mathrm{f}$ of Rais et al. provides an illustrative example, where $M b d 3^{\text {fl/ }}$ - cells appear to revert to pluripotency at an accelerated rate relative to controls. Expression data from the study do not support that finding, which may have been construed on the basis of GFP output alone. $\mathrm{Mbd}^{+/+}$cells, where Oct4-GFP is driven by the $\triangle \mathrm{PE}$ reporter, would be expected to yield profoundly reduced fluorescence signal relative to a variant based on the full promoter sequence.

During reprogramming, partially reverted intermediates are inherently produced en route to iPS cell colony

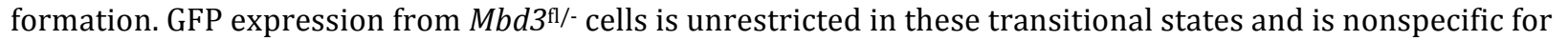
ground state pluripotency. This shortcoming is exacerbated by the authors' use of serum replacement factors (e.g. KSR) in culture media, which abolishes specificity for naïve pluripotent cells conferred by inhibition of glycogen synthase kinase 3 (GSK3) and mitogen-activated protein kinase pathways ${ }^{20}$. Numerous Oct4-GFP transgene insertions present in $M b d 3^{\text {HI/- }}$ (up to 24) and $\mathrm{Mbd3}^{+/+}$(up to 38) cells were uncharacterized with respect to the regulatory context of integration sites, potentially leading to spurious GFP activation unrelated to complete reprogramming state or the expression of endogenous Oct4.

Appropriate controls were not implemented for the reprogramming system utilized in Rais et al. $\mathrm{Mbd}^{+/+}$

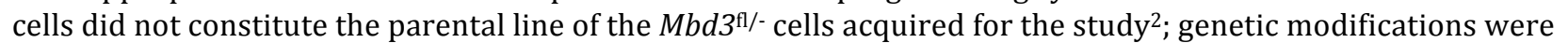
delivered separately to $M b d 3^{\text {II/- }}$ and $M b d 3^{+/+}$primary and secondary donor cells; random transgene integrations were not assessed in any condition; and cell lines were independently derived. Reprogramming experiments were performed in permissive conditions and cells were transformed with excessive Oct4-GFP transgene copies such that fluorescence activation is likely to be misregulated. All of these factors contribute to considerable experimental variation and impair the determination of biological significance. Assays in which incompatible fluorescence reporters are directly compared cannot be considered valid.

Assessment of Mbd3/NuRD function in reprogramming must be conducted with validated Mbd3-null cells, compatible and equivalent genetic modifications in test and control conditions, rigorous evaluation of authentic pluripotent cells and reprogramming outcomes, and matched cell lines from an isogenic parental background.

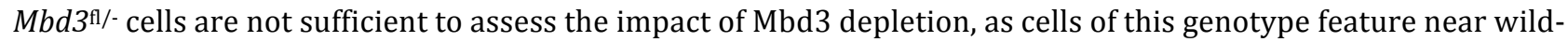
type transcript levels and protein abundance. In the absence of independent verification and in light of the deficiencies outlined above, results presented in Rais et al. describing 100\% reprogramming efficiency based on

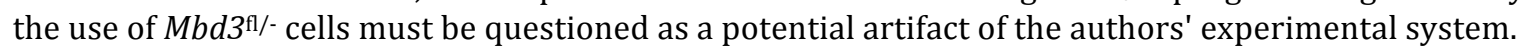




\section{Concluding remarks}

We brought this matter to the attention of the authors, and upon receiving an unsatisfactory explanation for the disparities found, ultimately raised the issue with Nature. The editors declined to publish our exchange as a contribution to the Communications Arising section, and instead encouraged the authors to post a comment to the Nature website ${ }^{21}$. The comment makes readers aware of a difference in Oct4-GFP reporter usage, but the significance of this issue and its implications for the study as a whole are diminished. We therefore issue this letter as an expression of concern to investigators who would follow this work.

\section{Acknowledgements}

We are grateful to Austin Smith and Wolfgang Huber for helpful discussions and advice.

\section{Methods}

\section{Microarray data analysis}

Affymetrix Mouse Gene 1.0 ST array data were obtained from GEO22 record GSE45352 ${ }^{8}$ and processed with the oligo Bioconductor package ${ }^{23}$. Microarray data were normalized with the robust multi-array average (RMA) method $^{23}$. Transcript clusters were mapped to mouse gene annotation based on release 78 of Ensembl25.

\section{Mbd3 transcript expression}

Microarray probesets targeting $M b d 3$ were originally assigned a value of 1 in the crosshyb_type field of the Affymetrix design files, indicating each probe in the Mbd3 transcript cluster (10370824) to be unique with respect to other putatively transcribed sequences targeted by the array. No additional perfect matches were found to any other mouse transcript annotated in Ensembl release 78, consistent with the assessment of crosshybridization potential carried out at design time. Heterozygous knockout ( $M b d 3^{\mathrm{fl} /}-$ ) cells had been targeted such that exons 2-7 were replaced with the $\beta$-geo selection marker, leaving exon 1 and UTR sequences intact ${ }^{10}$. To discount residual contribution from the non-functional allele, sense-orientation probe sequences were mapped to the reverse complement of $M b d 3$ genomic DNA, and probes corresponding to exon 1 (84510, 233909, 995596, 1042262), 5' UTR $(314091,646154,26469)$ and 3' UTR $(1028146,391255,585086,333495)$ were deleted from the pd.mogene.1.0.st.v1 annotation database ${ }^{26}$ prior to normalization. Expression levels were estimated as described above from the remaining 20 of 31 original probes spanning the Mbd3 locus. Probe-level data were plotted with the GenomeGraphs Bioconductor package ${ }^{27}$.

\section{ChIP-seq data analysis}

Illumina sequencing data deposited under accessions SRP028718 ${ }^{8}$ and SRX00054528 were obtained from the Sequence Read Archive ${ }^{29}$ and aligned to the mouse genome GRCm38 (mm10) using BWA ${ }^{30}$, allowing permissive treatment of low-quality base calls (-1 25 -q 20 ). For conservative copy number estimation, duplicate reads likely arising from PCR amplification were removed with Picard ${ }^{31}$, and suboptimal alignments (-q 10) filtered with SAMtools ${ }^{32}$. Focal gains corresponding to transgene insertions were estimated from genomic DNA (WCE, whole-cell extract) samples, accounting for $\mathrm{G} / \mathrm{C}$ content $^{33}$ and assuming ploidy $=2$ over windows of $1-10 \mathrm{~kb}$. Read density was computed with F-Seq ${ }^{34}$ and visualized in the Integrative Genomics Viewer ${ }^{35}$.

\section{References}

1. Zhang, Y., et al. Analysis of the NuRD subunits reveals a histone deacetylase core complex and a connection with DNA methylation. Genes Dev. 13, 1924-35 (1999)

2. Kaji, K., et al. The NuRD component Mbd3 is required for pluripotency of embryonic stem cells. Nat Cell Biol. 8, 285-92 (2006)

3. Reynolds, N., et al. NuRD-mediated deacetylation of H3K27 facilitates recruitment of Polycomb Repressive Complex 2 to direct gene repression. EMBO J. 31, 593-605 (2012)

4. Costa, Y., et al. NANOG-dependent function of TET1 and TET2 in establishment of pluripotency. Nature 495, 370-4 (2013)

5. Gagliardi, A., et al. A direct physical interaction between Nanog and Sox2 regulates embryonic stem cell self-renewal. EMBO J. 32, 2231-47 (2013)

6. van den Berg, D.L., et al. An Oct4-centered protein interaction network in embryonic stem cells. Cell Stem Cell 6, 369-81 (2010)

7. Pardo, M., et al. An expanded Oct4 interaction network: implications for stem cell biology, development, and disease. Cell Stem Cell 6, 382-95 (2010) 
bioRxiv preprint doi: https://doi.org/10.1101/013904; this version posted January 16,2015 . The copyright holder for this preprint (which was not certified by peer review) is the author/funder, who has granted bioRxiv a license to display the preprint in perpetuity. It is made available under aCC-BY 4.0 International license.

8. Rais, Y. et al. Deterministic direct reprogramming of somatic cells to pluripotency. Nature 502, 65-70 (2013)

9. dos Santos, R.L., et al. MBD3/NuRD facilitates induction of pluripotency in a context-dependent manner. Cell Stem Cell 15, 102-10 (2014)

10. Hendrich, B., Guy, J., Ramsahoye, B., Wilson, V.A. \& Bird, A. Closely related proteins MBD2 and MBD3 play distinctive but interacting roles in mouse development. Genes Dev. 15, 710-23 (2001)

11. Reynolds, N., et al. NuRD suppresses pluripotency gene expression to promote transcriptional heterogeneity and lineage commitment. Cell Stem Cell 10, 583-94 (2012)

12. Kirchhof, N., et al. Expression pattern of Oct-4 in preimplantation embryos of different species. Biol Reprod. 63, 1698-705 (2000)

13. Sylvester, I. \& Scholer, H.R. Regulation of the Oct-4 gene by nuclear receptors. Nucleic Acids Res. 22, $901-11$ (1994)

14. Yeom, Y.I., et al. Germline regulatory element of Oct-4 specific for the totipotent cycle of embryonal cells. Development 122, 881-94 (1996)

15. Sommer, C.A., et al. Induced pluripotent stem cell generation using a single lentiviral stem cell cassette. Stem Cells 27, 543-9 (2009)

16. Kehler, J., et al. Oct4 is required for primordial germ cell survival. EMBO Rep. 5, 1078-83 (2004)

17. Han, D.W., et al. Epiblast stem cell subpopulations represent mouse embryos of distinct pregastrulation stages. Cell 143, 617-27 (2010)

18. Frum, T., et al. Oct4 cell-autonomously promotes primitive endoderm development in the mouse blastocyst. Dev Cell $\mathbf{2 5}$, 610-22 (2013)

19. Le Bin, G.C., et al. Oct4 is required for lineage priming in the developing inner cell mass of the mouse blastocyst. Development 141, 1001-10 (2014)

20. Silva, J., et al. Promotion of reprogramming to ground state pluripotency by signal inhibition. PLoS Biol. 6, e253 (2008)

21. http://www.nature.com/nature/journal/v502/n7469/full/nature12587.html\# comment-64027

22. Barrett, T., et al. NCBI GEO: archive for functional genomics data sets-update. Nucleic Acids Res. 41, D991-5 (2013)

23. Carvalho, B.S. \& Irizarry, R.A. A framework for oligonucleotide microarray preprocessing. Bioinformatics 26, 2363-7 (2010)

24. Irizarry, R.A., et al. Exploration, normalization, and summaries of high density oligonucleotide array probe level data. Biostatistics 4, 249-264 (2003)

25. Cunningham, F., et al. Ensembl 2015. Nucleic Acids Res. gku1010 (2014)

26. Carvalho, B. pd.mogene.1.0.st.v1: platform design info for Affymetrix MoGene-1_0-st-v1. R package version 3.10.0.

27. Durinck, S., Bullard, J., Spellman, P.T. \& Dudoit, S. GenomeGraphs: integrated genomic data visualization with R. BMC Bioinformatics 10, 2 (2009)

28. Chen, X., et al. Integration of external signaling pathways with the core transcriptional network in embryonic stem cells. Cell 133, 1106-17 (2008)

29. Leinonen, R., Sugawara, H., Shumway, M; International Nucleotide Sequence Database Collaboration. The sequence read archive. Nucleic Acids Res. 39, D19-21 (2011)

30. Li, H. \& Durbin, R. Fast and accurate short read alignment with Burrows-Wheeler Transform. Bioinformatics 25, 1754-60 (2009)

31. http://broadinstitute.github.io/picard

32. Li, H., et al. The Sequence Alignment/Map (SAM) format and SAMtools. Bioinformatics 25, 2078-9 (2009)

33. Boeva, V., et al. Control-free calling of copy number alterations in deep-sequencing data using GC-content normalization. Bioinformatics 15, 268-9 (2011)

34. Boyle, A.P., Guinney, J., Crawford, G.E. \& Furey, T.S. F-Seq: a feature density estimator for high-throughput sequence tags. Bioinformatics 24, 2537-8 (2008)

35. Thorvaldsdóttir, H., Robinson, J.T. \& Mesirov, J.P. Integrative Genomics Viewer (IGV): high-performance genomics data visualization and exploration. Brief Bioinform. 14, 178-92 (2012) 